\title{
Insights into the Cytoadherence Phenomenon of Plasmodium vivax: The Putative Role of Phosphatidylserine
}

OPEN ACCESS

Edited by: Alexandre Morrot, Federal University of Rio de Janeiro, Brazil

Reviewed by: Pollyanna Stephanie Gomes, UFRJ, Brazil Sunil Joshi, Old Dominion University, United States

*Correspondence: Paulo Renato Totino prtotino@ioc.fiocruz.br

Specialty section: This article was submitted to Microbial Immunology, a section of the journal

Frontiers in Immunology

Received: 31 July 2017 Accepted: 30 August 2017 Published: 20 September 2017

Citation:

Totino PR and Lopes SC (2017) Insights into the Cytoadherence Phenomenon of Plasmodium vivax: The Putative Role of Phosphatidylserine.

Front. Immunol. 8:1148. doi: 10.3389/fimmu.2017.01148

\author{
Paulo Renato Totino ${ }^{1 *}$ and Stefanie Costa Lopes ${ }^{2}$ \\ ${ }^{1}$ Laboratory of Malaria Research, Instituto Oswaldo Cruz, Fundação Oswaldo Cruz, Rio de Janeiro, Brazil, ${ }^{2}$ Instituto \\ Leônidas e Maria Deane, Fundação Oswaldo Cruz, Manaus, Brazil
}

Plasmodium vivax is the most geographically widespread and the dominant human malaria parasite in most countries outside of sub-Saharan Africa and, although it was classically recognized to cause benign infection, severe cases and deaths caused by P. vivax have remarkably been reported. In contrast to Plasmodium falciparum, which well-known ability to bind to endothelium and placental tissue and form rosettes is related to severity of the disease, it has been a dogma that $P$. vivax is unable to undergo cytoadherent phenomena. However, some studies have demonstrated that red blood cells (RBCs) infected by $P$. vivax can cytoadhere to host cells, while the molecules participating in this host-parasite interaction are still a matter of speculation. In the present overview, we address the evidences currently supporting the adhesive profile of $P$. vivax and, additionally, discuss the putative role of phosphatidylserine-a cell membrane phospholipid with cytoadhesive properties that has been detected on the surface of Plasmodium-parasitized RBCs.

Keywords: Plasmodium vivax, cytoadhesion, rosetting, eryptosis, phosphatidylserine

\section{INTRODUCTION}

Plasmodium vivax is the most geographically widespread and the second most prevalent parasite causing malaria in the world, with about $35 \%$ of global population living at risk of infection (1) and an estimated 8.5 million symptomatic cases in 2015 (2). P. vivax contributes significantly to malaria cases outside of sub-Saharan Africa, where it accounts for $41 \%$ of the cases, of which $65 \%$ occur in South-East Asia, 19\% in Eastern Mediterranean, and the remaining in Western Pacific (9\%) and American (7\%) regions (2).

Despite its considerable impact in global public health, $P$. vivax was for long time a neglected parasite. The reasons for this scenario include: the low global prevalence [4\% (2)], when compared with the most prevalent and lethal malaria parasite, Plasmodium falciparum; the failure to adapt to in vitro culture conditions; as well as the classically recognized benign profile of infection (3). However, in the last decade, severe cases and deaths due to $P$. vivax infection have remarkably been reported in all endemic regions, driving the attention of the academic community to the real importance of $P$. vivax (4). Moreover, the occurrence of severe forms of malaria in P. vivax infections, such as cerebral malaria and placental malaria, which were previously reported to be exclusively associated with $P$. falciparum, suggests that $P$. vivax can, to some extent, present pathogenic profiles similar to $P$. falciparum (5-8). 
It is known that the main pathological phenomenon related to high virulence of $P$. falciparum is the sequestration of parasitized red blood cells (pRBC) to vascular endothelium and placenta, which allows late-stage forms of parasite to evade splenic phagocytosis, while provoking host damage by obstructing blood flow and inducing local pro-inflammatory response (9). Additional factors contributing to the pathogenesis of falciparum malaria comprise rosetting of $\mathrm{pRBC}$ with non-parasitized red blood cells (nRBC) as well as clumping of pRBC mediated by platelets (10). All these cytoadhesive events of $P$. falciparum-pRBC are recognized to be mediated by a large and diverse family of parasite antigens, named $P$. falciparum erythrocyte membrane protein 1 (PfEMP1), that is expressed on the surface of pRBC and shows affinity to several host receptors, including intercellular adhesion molecule 1 (ICAM-1), platelet-endothelial cell adhesion molecule 1, chondroitin sulfate A (CSA), hyaluronic acid (HA), thrombospondin (TSP), and CD36 (10). Since homologous of var genes, which encode PfEMP1, have not been identified in other Plasmodium species and the cytoadherence of $\mathrm{pRBC}$ was not consistently documented in non-falciparum malaria, it was believed that the cytoadherence phenomenon of $\mathrm{pRBC}$ was restricted to $P$. falciparum infection (11-14). However, some evidences currently support that red blood cells (RBCs) infected by $P$. vivax (Pv-pRBC) also undergo cytoadherence events, as addressed below in the present paper.

\section{EVIDENCES OF P. vivax CYTOADHESION}

Since Pv-pRBC lack adhesive knob structure and, especially, because all parasite stages can be observed in the peripheral blood of patients, it has been a dogma that $P$. vivax lacks the ability to cytoadhere and, therefore, to sequester. However, in 2010 it was demonstrated, for the first time, that $\mathrm{Pv}$-pRBC are able to cytoadhere in vitro to host cells (15). In this study, Pv-pRBC obtained from Brazilian non-severe patient samples were tested by static and flow cytoadhesion assays using human lung endothelial cells (HLEC), monkey brain endothelial cells, and human placental cryosections. Although the number of $\mathrm{Pv}$-pRBC adhered under static conditions was lower than that observed for $\mathrm{pRBC}$ infected by $P$. falciparum, the strength of interaction with endothelium was similar. Moreover, it was shown using transfected Chinese Hamster Ovarian (CHO) cells that the binding of Pv-pRBC to ICAM-1-expressing cells was twice as high as to non-transfected cells or CD36-expressing cells and that the adherence to placental cryosections and HLEC was inhibited by soluble CSA, suggesting involvement of both ICAM-1 and CSA in adhesive processes of $P$. vivax. In fact, the adhesive capacity of $\mathrm{Pv}$-pRBC to HLEC and the involvement of ICAM-1 were later recorded in studies using $P$. vivax isolates from Colombia (16). Moreover, a treatment with chondroitinase reversed the adherence of $P$. vivax isolates from the Asia-Pacific region to immobilized CSA, while it was additionally observed that hyaluronidase disturbed Pv-pRBC adhesion mediated by HA (17). Nevertheless, the degree of commitment of each host adhesive receptor studied until now is still a matter of speculation. For instance, in the study with Thai patients described above, all $P$. vivax isolates were adherent to immobilized CSA and HA, but none adhered to ICAM-1 (17), and when $P$. vivax isolates from Brazilian Amazon region was evaluated, a low frequency of $\mathrm{pRBC}$ adhesion to ICAM-1 and CSA was observed (18).

Corroborating the adhesive profile of $P$. vivax, it was recently reported that the schizont stage was absent in the peripheral circulation in more than half of Brazilian patients diagnosed with $P$. vivax malaria by blood smears and, even when $P$. vivax schizonts were detected, they were mostly present at low frequency (19). Moreover, in vitro maturation of $P$. vivax isolates provided a greater ability of Pv-pRBC to cytoadhere to HLEC than the same isolates before maturation, revealing a higher adhesive capacity of mature forms. These data indicate that $P$. vivax might be sequestered in the deep vasculature and that maturation of late stages of $P$. vivax occur outside peripheral circulation. Actually, more than 50 years ago sequestration of $\mathrm{Pv}-\mathrm{pRBC}$ was proposed by Field et al. (20), who showed a disappearance of schizonts from the peripheral blood of a $P$. vivax patient. In addition, recent discoveries showing accumulation of $P$. vivax schizonts and gametocytes in the bone marrow (21); detection of a large number of intact $\mathrm{Pv}$-pRBC in the spleen (22); and presence of Pv-pRBC within pulmonary microvasculature from a patient with negative blood smear at the time of death (23) support the hypothesis that $P$. vivax has the ability to sequester.

Although P. vivax does not present any protein homologous to PfEMP1, a group of variable proteins (VIR proteins) is expressed by this parasite species (24). In contrast to PfEMP1, VIR proteins are not clonally expressed and can additionally be found within pRBC, indicating initially that these $P$. vivax antigens have different functions from PfEMP1 ones (25). However, based on their variant nature and presence on $\mathrm{pRBC}$ surface, the role of VIR antigens in Pv-pRBC adhesion has been evaluated. Thus, computational analysis using a $P$. falciparum-based algorithm revealed putative adhesive protein motifs in VIR proteins (26), which could explain the capacity of vir gene (VIR-14) to mediate adhesion of pRBC to ICAM-1 when transfected into a non-adhesive P. falciparum line (27). Also, consistent with the participation of VIR proteins in the sequester phenomenon of $\mathrm{Pv}$-pRBC, it was previously demonstrated that antibodies against variants of VIR proteins (VIR-A4 and VIR-E5) partially inhibit adhesion of Pv-pRBC to HLEC (15).

Therefore, there is now a growing body of evidence supporting that $P$. vivax parasites possess adhesive phenotypes. Indeed, besides adhesion to endothelium and placental tissue, it is known that $P$. vivax has the ability to form rosettes, which are defined by the binding of a $\mathrm{pRBC}$ with two or more $\mathrm{nRBC}$. Rosetting formation in $P$. vivax infection was described more than 20 years ago (28) and has been shown to be more frequent than in $P$. falciparum infection $(29,30)$, but few studies have been conducted to investigate this $P$. vivax phenomenon; largely due to the absence of a $P$. vivax continuous culture method. Notwithstanding, it was already demonstrated that rosettes in $P$. vivax infection are formed by interaction of pRBC containing trophozoites, schizonts, or gametocytes with mature RBCs (normocytes), a process that involves glycophorin $C$ receptor present on nRBC surface (30). Furthermore, $P$. vivax rosettes were shown to be stable even under high physiological shear stress and rosette formation was closely associated with induction of an increased rigidity of Pv-pRBC, 
possibly contributing to sequestration of $P$. vivax in the microvasculature (31). However, differently from $P$. falciparum, both host and parasite antigens intricate on $P$. vivax rosetting as well as the relation of this adhesive phenomenon to the pathogenesis of vivax malaria remain unknown.

\section{THE ROLE OF PHOSPHATIDYLSERINE (PS) IN CYTOADHESIVE PHENOMENA}

While some research efforts have been dedicated to identifying $P$. vivax antigens participating in cytoadhesion of $\mathrm{pRBC}$, little attention has been given to host $\mathrm{RBC}$ factors that have adhesive potentiality, such as PS. PS is a cell membrane phospholipid usually restricted to the inner leaflet of the lipid bilayer (32), but during apoptotic cell death processes PS is exposed on cell surface, promoting recognition and clearance of dying cells by phagocytes (33). Externalization of PS also occurs in activated platelet and transiently in activated lymphocytes and mast cells, where it is associated with procoagulant activity, homing to sites of inflammation and cell degranulation, respectively (34-36). Furthermore, it has been shown that the presence of PS on external leaflet of cell membrane is a hallmark of suicidal erythrocyte death, named eryptosis (37).

Eryptosis occurs in senescent RBC and can precociously be triggered by a variety of endogenous and xenobiotics stimuli $(38,39)$. Similarly to apoptosis of nucleated cells, eryptotic processes are characterized by many morphological and biochemical changes, i.e., $\mathrm{Ca}^{2+}$ influx, cysteine protease activity, PS exposure, cell shrinkage, and plasma membrane microvesiculation, with externalized PS rendering RBC susceptible to clearance by splenic phagocytes (40). Accordingly, overinduction of PS-exposing eryptotic RBC is believed to contribute to the development of anemia related to several clinical disorders, as reported in both experimental and human malaria $(41,42)$. But, additionally, PS on RBC surface is also considered one of the factors responsible for thrombo-occlusive events in pathologies such as sickle cell disease, chronic renal failure, retinal vein occlusion, and diabetes; in part, by mediating $\mathrm{RBC}$ adherence to endothelium as well as cell aggregation (43-46).

Indeed, adherence of PS-exposing RBC to endothelium is observed in vitro under dynamic flow conditions mimicking venular wall shear stress $(47,48)$ and takes place through interaction of PS with the scavenger receptors CD36 or CXC chemokine ligand 16 (CXCL16) expressed on endothelial cell membrane, as well as with TSP, which is found in the basement membrane and extracellular matrix of endothelium and that can be exposed by vascular injury $(45,48,49)$. Moreover, soluble plasma TSP can interact with CD36 and, in this manner, could operate as a bridge to adherence of PS-exposing RBC $(50,51)$. Such interactions involving PS, CD36, TSP, and CXCL16 have also been involved in RBC-platelet aggregation, agreeing with the presence of CD36 and CXCL16 in platelet membrane (52-54). Thus, if parasite antigens able to provide $\mathrm{pRBC}$ adhesiveness are absent, $P$. vivax could explore host adhesive molecules to mediate cytoadhesive events of pRBC.

Interestingly, it has previously been demonstrated that intraerythrocytic plasmodia development progressively induces PS exteriorization on $\mathrm{pRBC}$, with larger exposure at the late stages of parasite maturation $(55,56)$, which possibly result from eryptosis stimulation. Schizogonic process is described to activate non-selective cation channels in host pRBC membrane, allowing the entry of $\mathrm{Ca}^{2+}$ necessary for parasite intracellular growth, which, in turn, leads to the activation of phospholipid scramblases responsible for PS exposure (57). Although PS externalization has not been evaluated in $P$. vivax infection, it was already detected by flow cytometry in RBC infected by $P$. falciparum, $P$. berghei, and $P$. yoelii $(41,58,59)$ and in $P$. falciparum, the binding of late-stage pRBC exposing PS to CD36-expressing cells as well as immobilized CD36 and TSP was inhibited by annexin V, PS-containing liposomes or glycerophosphorylserine-a soluble form of PS (60), indicating that PS could, at least in part, support cytoadhesive phenomena of $\mathrm{pRBC}$ in malaria. Consistent with this possibility, a relationship between cytoadhesive activity and PS exposure was also reported when knobby and knobless $P$. falciparum strains, which differentially induce PS externalization on late-stage pRBC, were studied (60) and, more recently, it was also shown that PS-expressing RBC can operate as nuclei for RBC aggregation induced by $P$. falciparum-conditioned medium (61).

Importantly, studies conducted on P. berghei ANKA experimental infection with CD36-deficient rodents have demonstrated that CD36 is an essential receptor for sequestration of schizont-stage pRBC, which occurred mostly in the capillaries of lungs and adipose tissue, but not in the brain, where endothelial expression of CD36 is low or absent (62). Indeed, besides being incriminated in acute tissue injury induced by $P$. berghei ANKA-pRBC accumulation in lung (63), CD36 is known as an important receptor mediating $\mathrm{pRBC}$ sequestration, non-related to brain and placental tissue in P. falciparum malaria (64), and its expression on surface of platelets and RBC has been implicated in clumping and rosetting processes of $P$. falciparum-pRBC, respectively $(65,66)$. However, it is noteworthy that, in contrast to $P$. falciparum, which expresses the adhesin PfEMP1, but similarly to Plasmodium chabaudi, whose late-stage forms undergo CD36-dependent cytoadhesion in vitro (67), no putative parasite ligand for CD36 has been identified in genome of $P$. berghei, or even other species of Plasmodium displaying cytoadherence phenotypes, such as $P$. vivax $(14,68)$, reinforcing the premise that alternative pathways, not based on the expression of parasite adhesins, could mediate CD36-dependent cytoadhesion of latestage $\mathrm{pRBC}$.

Additional evidences for this proposition are also documented in $P$. vivax malaria. First, a reduction in $\mathrm{Pv}-\mathrm{pRBC}$ adhesion to HLEC was achieved in the presence of anti-CD36 antibodies, although the small number of samples limited the statistical analysis concerning extension of CD36 participation in $P$. vivax cytoadhesion (15). Second, while studying cellular trafficking and the adhesive propriety of $P$. vivax VIR proteins in $P$. falciparum transgenic lines, it was shown that only one variant of VIR proteins (VIR-14) was exposed at the surface of pRBC, mediating cytoadherence to $\mathrm{CHO}$ cells through ICAM-1, but not CD36 (27). Thus, it is tempting to speculate that if antigens encoded by vir genes participate in $\mathrm{Pv}$-pRBC adhesive events, it seems that it does not take place through a CD36-dependent mechanism, in which PS could play a role (Figure 1). In view of this possibility, 


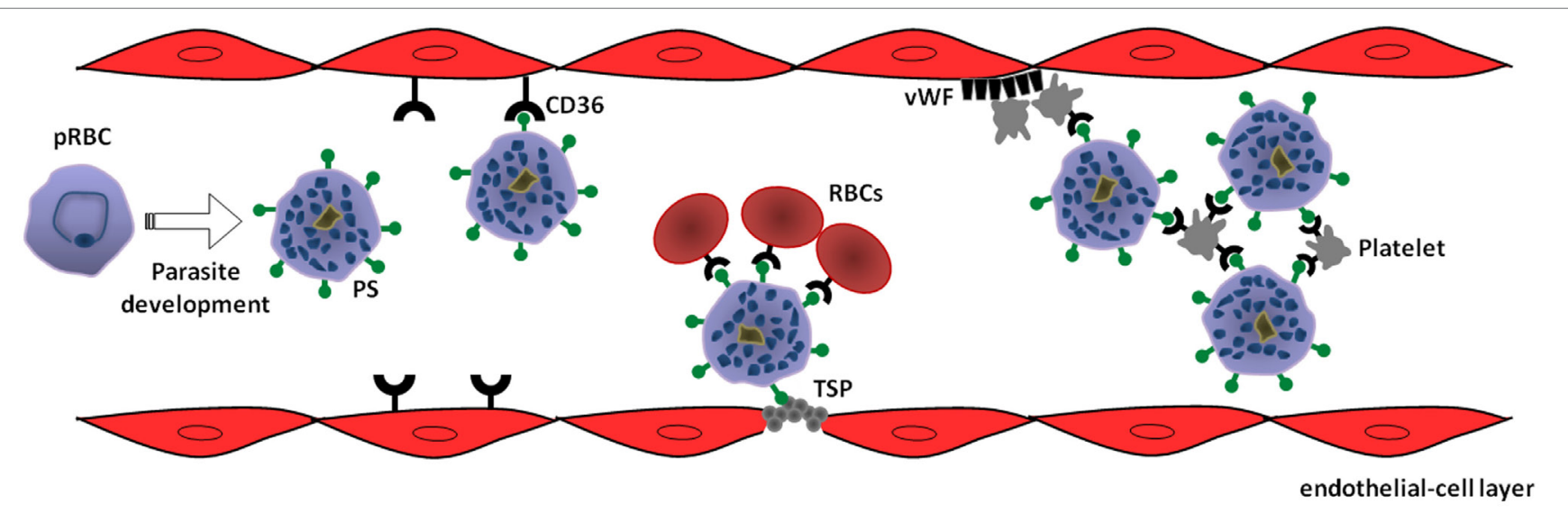

FIGURE 1 | Model of phosphatidylserine (PS) role in cytoadhesive phenomena of Plasmodium vivax-parasitized red blood cells (pRBC). Intraerythrocytic parasite development leads to exposure of PS on pRBC surface as a result of suicidal erythrocyte death (eryptosis) induction. In turn, PS mediates sequestration of pRBC to microvasculature through interaction with receptors expressed on endothelial cells, such as CD36, or thrombospondin (TSP) exposed in injured endothelium. In a CD36-dependent manner, PS-exposing pRBC can promote rosetting of non-parasitized red blood cells (RBCs) as well as autoagglutination (clumping) by binding to platelets. Additionally, von Willebrand factor (VWF) can indirectly contribute to the sequestration of PS-exposing pRBC by mediating platelet adhesion at sites of vascular damage (69).

studies evaluating the occurrence of PS externalization in $\mathrm{pRBC}$ from $P$. vivax isolates as well as the effect of blocking PS-CD36/ TSP interaction on adhesive phenomena of Pv-pRBC may help to confirm the involvement of PS in vivax malaria.

\section{REFERENCES}

1. World Health Organization. Control and Elimination of Plasmodium vivax Malaria: A Technical Brief. Geneva: World Health Organization (2015).

2. World Health Organization. World Malaria Report 2016. Geneva: World Health Organization (2016).

3. Baird JK. Neglect of Plasmodium vivax malaria. Trends Parasitol (2007) 23: 533-9. doi:10.1016/j.pt.2007.08.011

4. Rahimi BA, Thakkinstian A, White NJ, Sirivichayakul C, Dondorp AM, Chokejindachai W. Severe vivax malaria: a systematic review and metaanalysis of clinical studies since 1900. Malar J (2014) 13:481. doi:10.1186/ 1475-2875-13-481

5. Tjitra E, Anstey NM, Sugiarto P, Warikar N, Kenangalem E, Karyana M, et al. Multidrug-resistant Plasmodium vivax associated with severe and fatal malaria: a prospective study in Papua, Indonesia. PLoS Med (2008) 5:e128. doi:10.1371/journal.pmed.0050128

6. Naing C, Whittaker MA, Nyunt Wai V, Mak JW. Is Plasmodium vivax malaria a severe malaria? A systematic review and meta-analysis. PLoS Negl Trop Dis (2014) 8:e3071. doi:10.1371/journal.pntd.0003071

7. Chaikitgosiyakul S, Rijken MJ, Muehlenbachs A, Lee SJ, Chaisri U, Viriyavejakul P, et al. A morphometric and histological study of placental malaria shows significant changes to villous architecture in both Plasmodium falciparum and Plasmodium vivax infection. Malar J (2014) 13:4. doi:10.1186/1475-2875-13-4

8. Datta M, Biswas J, Dasgupta S, Banerjee K, Choudhury S, Sengupta SK, et al. Comparative study on antenatal and perinatal outcome of vivax and falciparum malaria in a Tertiary Care Hospital of Kolkata, India. J Clin Diagn Res (2017) 11:QC01-04. doi:10.7860/JCDR/2017/23051.9195

9. Miller LH, Baruch DI, Marsh K, Doumbo OK. The pathogenic basis of malaria. Nature (2002) 415:673-9. doi:10.1038/415673a

10. Rasti N, Wahlgren M, Chen Q. Molecular aspects of malaria pathogenesis. FEMS Immunol Med Microbiol (2004) 41:9-26. doi:10.1016/j.femsim.2004.01.010

11. Korir CC, Galinski MR. Proteomic studies of Plasmodium knowlesi SICA variant antigens demonstrate their relationship with $P$. falciparum EMP1. Infect Genet Evol (2006) 6:75-9. doi:10.1016/j.meegid.2005.01.003

\section{AUTHOR CONTRIBUTIONS}

PT and SL wrote the paper. Both authors read and approved the final version of the manuscript.

12. Mueller I, Galinski MR, Baird JK, Carlton JM, Kochar DK, Alonso PL, et al. Key gaps in the knowledge of Plasmodium vivax, a neglected human malaria parasite. Lancet Infect Dis (2009) 9:555-66. doi:10.1016/S1473-3099(09)70177-X

13. Maguire JD, Baird JK. The 'non-falciparum' malarias: the roles of epidemiology, parasite biology, clinical syndromes, complications and diagnostic rigour in guiding therapeutic strategies. Ann Trop Med Parasitol (2010) 104:283-301. doi:10.1179/136485910X12743554760027

14. Ebbinghaus P, Krücken J. Characterization and tissue-specific expression patterns of the Plasmodium chabaudi cir multigene family. Malar J (2011) 10:272. doi:10.1186/1475-2875-10-272

15. Carvalho BO, Lopes SC, Nogueira PA, Orlandi PP, Bargieri DY, Blanco YC, et al. On the cytoadhesion of Plasmodium vivax-infected erythrocytes. J Infect Dis (2010) 202:638-47. doi:10.1086/654815

16. De las Salas B, Segura C, Pabón A, Lopes SC, Costa FT, Blair S. Adherence to human lung microvascular endothelial cells (HMVEC-L) of Plasmodium vivax isolates from Colombia. Malar J (2013) 12:347. doi:10.1186/1475-2875-12-347

17. Chotivanich K, Udomsangpetch R, Suwanarusk R, Pukrittayakamee S, Wilairatana $\mathrm{P}$, Beeson JG, et al. Plasmodium vivax adherence to placental glycosaminoglycans. PLoS One (2012) 7:e34509. doi:10.1371/journal.pone. 0034509

18. Marín-Menéndez A, Bardají A, Martínez-Espinosa FE, Bôtto-Menezes C, Lacerda MV, Ortiz J, et al. Rosetting in Plasmodium vivax: a cytoadhesion phenotype associated with anaemia. PLoS Negl Trop Dis (2013) 7:e2155. doi:10.1371/journal.pntd.0002155

19. Lopes SC, Albrecht L, Carvalho BO, Siqueira AM, Thomson-Luque R, Nogueira PA, et al. Paucity of Plasmodium vivax mature schizonts in peripheral blood is associated with their increased cytoadhesive potential. J Infect Dis (2014) 209:1403-7. doi:10.1093/infdis/jiu018

20. Field JW, Sandosham AA, Fong YL. The Microscopial Diagnosis of Human Malaria. Kuala Lumpur: Institute for Medical Research (1963).

21. Baro B, Deroost K, Raiol T, Brito M, Almeida AC, de Menezes-Neto A, et al. Plasmodium vivax gametocytes in the bone marrow of an acute malaria patient and changes in the erythroid miRNA profile. PLoS Negl Trop Dis (2017) 11:e0005365. doi:10.1371/journal.pntd.0005365 
22. Siqueira AM, Magalhães BML, Melo GC, Ferrer M, Castillo P, MartinJaular L, et al. Spleen rupture in a case of untreated Plasmodium vivax infection. PLoS Negl Trop Dis (2012) 6:e1934. doi:10.1371/journal.pntd. 0001934

23. Lacerda MV, Fragoso SC, Alecrim MG, Alexandre MA, Magalhães BM, Siqueira AM, et al. Postmortem characterization of patients with clinical diagnosis of Plasmodium vivax malaria: to what extent does this parasite kill? Clin Infect Dis (2012) 55:e67-74. doi:10.1093/cid/cis615

24. del Portillo HA, Fernandez-Becerra C, Bowman S, Oliver K, Preuss M, Sanchez CP, et al. A superfamily of variant genes encoded in the subtelomeric region of Plasmodium vivax. Nature (2001) 410:839-42. doi:10.1038/35071118

25. Fernandez-Becerra C, Pein O, de Oliveira TR, Yamamoto MM, Cassola AC, Rocha C, et al. Variant proteins of Plasmodium vivax are not clonally expressed in natural infections. Mol Microbiol (2005) 58:648-58. doi:10.1111/ j.1365-2958.2005.04850.x

26. Lopez FJ, Bernabeu M, Fernandez-Becerra C, del Portillo HA. A new computational approach redefines the subtelomeric vir superfamily of Plasmodium vivax. BMC Genomics (2013) 14:8. doi:10.1186/1471-2164-14-8

27. Bernabeu M, Lopez FJ, Ferrer M, Martin-Jaular L, Razaname A, Corradin G, et al. Functional analysis of Plasmodium vivax VIR proteins reveals different subcellular localizations and cytoadherence to the ICAM-1 endothelial receptor. Cell Microbiol (2012) 14:386-400. doi:10.1111/j.1462-5822.2011.01726.x

28. Udomsangpetch R, Thanikkul K, Pukrittayakamee S, White NJ. Rosette formation by Plasmodium vivax. Trans $R$ Soc Trop Med Hyg (1995) 89:635-7. doi:10.1016/0035-9203(95)90422-0

29. Chotivanich KT, Pukrittayakamee S, Simpson JA, White NJ, Udomsangpetch R. Characteristics of Plasmodium vivax-infected erythrocyte rosettes. Am J Trop Med Hyg (1998) 59:73-6. doi:10.4269/ajtmh.1998.59.73

30. Lee WC, Malleret B, Lau YL, Mauduit M, Fong MY, Cho JS, et al. Glycophorin $\mathrm{C}$ (CD236R) mediates vivax malaria parasite rosetting to normocytes. Blood (2014) 123:e100-9. doi:10.1182/blood-2013-12-541698

31. Zhang R, Lee WC, Lau YL, Albrecht L, Lopes SC, Costa FT, et al. Rheopathologic consequence of Plasmodium vivax rosette formation. PLoS Negl Trop Dis (2016) 10:e0004912. doi:10.1371/journal.pntd.0004912

32. Op Den Kamp JAF. Lipid asymmetry in membranes. Ann Rev Biochem (1979) 48:47-71. doi:10.1146/annurev.bi.48.070179.000403

33. Wu Y, Tibrewal N, Birge RB. Phosphatidylserine recognition by phagocytes: a view to a kill. Trends Cell Biol (2006) 16:189-97. doi:10.1016/j.tcb.2006.02.003

34. Lhermusier T, Chap H, Payrastre B. Platelet membrane phospholipid asymmetry: from the characterization of a scramblase activity to the identification of an essential protein mutated in Scott syndrome. J Thromb Haemost (2011) 9:1883-91. doi:10.1111/j.1538-7836.2011.04478.x

35. Elliott JI, Surprenant A, Marelli-Berg FM, Cooper JC, Cassady-Cain RL, Wooding $\mathrm{C}$, et al. Membrane phosphatidylserine distribution as a nonapoptotic signalling mechanism in lymphocytes. Nat Cell Biol (2005) 7:808-16. doi:10.1038/ncb1279

36. Rysavy NM, Shimoda LM, Dixon AM, Speck M, Stokes AJ, Turner H, et al. Beyond apoptosis: the mechanism and function of phosphatidylserine asymmetry in the membrane of activating mast cells. Bioarchitecture (2014) 4:127-37. doi:10.1080/19490992.2014.995516

37. Lang KS, Lang PA, Bauer C, Duranton C, Wieder T, Huber SM, et al. Mechanisms of suicidal erythrocyte death. Cell Physiol Biochem (2005) 15:195-202. doi:10.1159/000086406

38. Bratosin D, Estaquier J, Ameisen JC, Montreuil J. Molecular and cellular mechanisms of erythrocyte programmed cell death: impact on blood transfusion. Vox Sang (2002) 83:307-10. doi:10.1111/j.1423-0410.2002. tb05324.x

39. Lang E, Lang F. Triggers, inhibitors, mechanisms, and significance of eryptosis: the suicidal erythrocyte death. Biomed Res Int (2015) 2015:513518. doi: $10.1155 / 2015 / 513518$

40. Totino PR, Daniel-Ribeiro CT, Ferreira-da-Cruz MF. Evidencing the role of erythrocytic apoptosis in malarial anemia. Front Cell Infect Microbiol (2016) 6:176. doi:10.3389/fcimb.2016.00176

41. Totino PR, Magalhães AD, Silva LA, Banic DM, Daniel-Ribeiro CT, Ferreirada-Cruz MF. Apoptosis of non-parasitized red blood cells in malaria: a putative mechanism involved in the pathogenesis of anaemia. Malar J (2010) 9:350. doi:10.1186/1475-2875-9-350

42. Fendel R, Brandts C, Rudat A, Kreidenweiss A, Steur C, Appelmann I, et al. Hemolysis is associated with low reticulocyte production index and predicts blood transfusion in severe malarial anemia. PLoS One (2010) 5:e10038. doi:10.1371/journal.pone.0010038

43. Wali RK, Jaffe S, Kumar D, Kalra VK. Alterations in organization of phospholipids in erythrocytes as factor in adherence to endothelial cells in diabetes mellitus. Diabetes (1988) 37:104-11. doi:10.2337/diabetes.37.1.104

44. Bonomini M, Sirolli V, Gizzi F, Di Stante S, Grilli A, Felaco M. Enhanced adherence of human uremic erythrocytes to vascular endothelium: role of phosphatidylserine exposure. Kidney Int (2002) 62:1358-63. doi:10.1111/j. 1523-1755.2002.kid560.x

45. Setty BN, Kulkarni S, Stuart MJ. Role of erythrocyte phosphatidylserine in sickle red cell-endothelial adhesion. Blood (2002) 99:1564-71. doi:10.1182/ blood.V99.5.1564

46. Wautier MP, Héron E, Picot J, Colin Y, Hermine O, Wautier JL. Red blood cell phosphatidylserine exposure is responsible for increased erythrocyte adhesion to endothelium in central retinal vein occlusion. J Thromb Haemost (2011) 9:1049-55. doi:10.1111/j.1538-7836.2011.04251.x

47. Closse C, Dachary-Prigent J, Boisseau MR. Phosphatidylserine-related adhesion of human erythrocytes to vascular endothelium. Br J Haematol (1999) 107:300-2. doi:10.1046/j.1365-2141.1999.01718.x

48. Manodori AB, Barabino GA, Lubin BH, Kuypers FA. Adherence of phosphatidylserine-exposing erythrocytes to endothelial matrix thrombospondin. Blood (2000) 95:1293-300.

49. Borst O, Abed M, Alesutan I, Towhid ST, Qadri SM, Föller M, et al. Dynamic adhesion of eryptotic erythrocytes to endothelial cells via CXCL16/SR-PSOX. Am J Physiol Cell Physiol (2012) 302:C644-51. doi:10.1152/ajpcell.00340.2011

50. Silverstein RL, Baird M, Lo SK, Yesner LM. Sense and antisense cDNA transfection of CD36 (glycoprotein IV) in melanoma cells. Role of CD36 as a thrombospondin receptor. J Biol Chem (1992) 267:16607-12.

51. Betal SG, Setty BNY. Phosphatidylserine-positive erythrocytes bind to immobilized and soluble thrombospondin-1 via its heparin-binding domain. Transl Res (2008) 152:165-77. doi:10.1016/j.trsl.2008.07.007

52. Ohta K, Fukuuchi Y, Tomita M, Tanahashi N, Matsuoka S, Takeda H. Monoclonal antibody against platelet thrombospondin decreases erythrocyte aggregation rate. Biorheology (1991) 28:551-6.

53. Wun T, Paglieroni T, Field CL, Welborn J, Cheung A, Walker NJ, et al. Plateleterythrocyte adhesion in sickle cell disease. J Investig Med (1999) 47:121-7.

54. Walker B, Towhid ST, Schmid E, Hoffmann SM, Abed M, Münzer P, et al. Dynamic adhesion of eryptotic erythrocytes to immobilized platelets via platelet phosphatidylserine receptors. Am J Physiol Cell Physiol (2014) 306: C291-7. doi:10.1152/ajpcell.00318.2013

55. Joshi P, Dutta GP, Gupta CM. An intracellular simian malarial parasite (Plasmodium knowlesi) induces stage-dependent alterations in membrane phospholipid organization of its host erythrocyte. Biochem J (1987) 246:103-8. doi: $10.1042 / \mathrm{bj} 2460103$

56. Schwartz RS, Olson JA, Raventos-Suarez C, Yee M, Heath RH, Lubin B, et al. Altered plasma membrane phospholipid organization in Plasmodium falciparum-infected human erythrocytes. Blood (1987) 69:401-7.

57. Lang F, Lang PA, Lang KS, Brand V, Tanneur V, Duranton C, et al. Channelinduced apoptosis of infected host cells - the case of malaria. Pflugers Arch (2004) 448:319-24. doi:10.1007/s00424-004-1254-9

58. Butthep P, Wanram S, Pattanapanyasat K, Vattanaviboon P, Fucharoen S, Wilairat P. Cytoadherence between endothelial cells and P. falciparum infected and noninfected normal and thalassemic red blood cells. Cytometry B Clin Cytom (2006) 70:432-42. doi:10.1002/cyto.b.20141

59. Alesutan I, Bobbala D, Qadri SM, Estremera A, Föller M, Lang F. Beneficial effect of aurothiomalate on murine malaria. Malar J (2010) 9:118. doi:10.1186/ 1475-2875-9-118

60. Eda S, Sherman IW. Cytoadherence of malaria-infected red blood cells involves exposure of phosphatidylserine. Cell Physiol Biochem (2002) 12:373-84. doi: $10.1159 / 000067908$

61. Balaji SN, Trivedi V. Extracellular methemoglobin primes red blood cell aggregation in malaria: an in vitro mechanistic study. FEBS Lett (2013) 587:350-7. doi:10.1016/j.febslet.2012.12.015

62. Franke-Fayard B, Janse CJ, Cunha-Rodrigues M, Ramesar J, Büscher P, Que I, et al. Murine malaria parasite sequestration: CD36 is the major receptor, but cerebral pathology is unlinked to sequestration. Proc Natl Acad Sci U S A (2005) 102:11468-73. doi:10.1073/pnas.0503386102

63. Lovegrove FE, Gharib SA, Peña-Castillo L, Patel SN, Ruzinski JT, Hughes TR, et al. Parasite burden and CD36-mediated sequestration are determinants 
of acute lung injury in an experimental malaria model. PLoS Pathog (2008) 4:e1000068. doi:10.1371/journal.ppat.1000068

64. Serghides L, Smith TG, Patel SN, Kain KC. CD36 and malaria: friends or foes? Trends Parasitol (2003) 19:461-9. doi:10.1016/j.pt.2003.08.006

65. van Schravendijk MR, Handunnetti SM, Barnwell JW, Howard RJ. Normal human erythrocytes express CD36, an adhesion molecule of monocytes, platelets, and endothelial cells. Blood (1992) 80:2105-14.

66. Arman M, Adams Y, Lindergard G, Rowe JA. A method for positive and negative selection of Plasmodium falciparum platelet-mediated clumping parasites and investigation of the role of CD36. PLoS One (2013) 8:e55453. doi:10.1371/journal.pone.0055453

67. Mota MM, Jarra W, Hirst E, Patnaik PK, Holder AA. Plasmodium chabaudiinfected erythrocytes adhere to CD36 and bind to microvascular endothelial cells in an organ-specific way. Infect Immun (2000) 68:4135-44. doi:10.1128/ IAI.68.7.4135-4144.2000

68. Frech C, Chen N. Variant surface antigens of malaria parasites: functional and evolutionary insights from comparative gene family classification and analysis. BMC Genomics (2013) 14:427. doi:10.1186/1471-216414-427

69. Ruggeri ZM. Von Willebrand factor, platelets and endothelial cell interactions. J Thromb Haemost (2003) 1:1335-42. doi:10.1046/j.1538-7836.2003.00260.x

Conflict of Interest Statement: The authors declare that the research was conducted in the absence of any commercial or financial relationships that could be construed as a potential conflict of interest.

The reviewer, PG, and handling editor declared their shared affiliation.

Copyright (C) 2017 Totino and Lopes. This is an open-access article distributed under the terms of the Creative Commons Attribution License (CC BY). The use, distribution or reproduction in other forums is permitted, provided the original author(s) or licensor are credited and that the original publication in this journal is cited, in accordance with accepted academic practice. No use, distribution or reproduction is permitted which does not comply with these terms. 